\title{
PERANCANGAN PEMASARAN ONLINE BERBASIS E-COMMERCE PADA PRODUK UMKM PD NESIF STUDI KASUS DI DESA DAYEUH MANGGUNG KECAMATAN CILAWU KABUPATEN GARUT
}

\author{
Ade Geovania Azwar ${ }^{1}$, Nurwathi ${ }^{2}$, Novi Mardiana ${ }^{3}$, Lina Nurhayati ${ }^{4}$, Djoko Pitoyo ${ }^{5}$, Ahmad \\ Munandar $^{6}$, Inayati Nasrudin ${ }^{7}$, Sofiani Nalwin ${ }^{8}$ \\ 1,2,3,5,6,7,8 Teknik Industri-Fakultas Teknik-Universitas Sangga Buana Bandung \\ ${ }^{4}$ Teknik Mesin-Fakultas Teknik-Universitas Sangga Buana Bandung \\ ${ }^{1}$ korespondensi : ade.geovania@ usbypkp.ac.id
}

\begin{abstract}
ABSTRAK
Peran UMKM dalam pembangunan ekonomi nasional sangat besar dan penting. UMKM diharapkan mampu bersaing dengan produk lainnya. Salah satu peluang yang dapat dilakukan dengan memperkenalkan calon konsumen kepada produk-produk UMKM melalui teknologi yakni E-Commerce. Pemilihan E-Commerce dilakukan dengan beberapa pertimbangan seperti jumlah pengguna aktif dan manfaat yang sudah dirasakan oleh UMKM. PD Nesif adalah satu UMKM produksen makanan yang masih menggunakan pemasaran secara tradisional. Tujuan Pengabdian pada Masyarakat ini adalah PD Nesif dapat memasukkan unsur teknologi dalam menjangkau calon konsumen dan tentu saja meningkatkan profit bagi PD Nesif. Hasil PkM menunjukkan bahwa Terdapat beberapa kendala yang dialami oleh PD Nesif yang berkaitan dengan waktu dan komitmen dalam pengelolaan Akun E-commerce yang telah dimiliki.
\end{abstract}

Kata Kunci: E-Commerce, UMKM, PD Nesif.

\section{ABSTRACT}

The role of MSMEs in national economic development is very large and important. SMEs are expected to be able to compete with other products. One of the opportunities that can be done is by introducing potential consumers to MSME products through technology, namely E-Commerce. The selection of E-Commerce is carried out with several considerations such as the number of active users and the benefits that have been felt by MSMEs. PD Nesif is a food production MSME that still uses traditional marketing. The purpose of this Community Service is that PD Nesif can incorporate elements of technology in reaching potential consumers and of course increasing profits for PD Nesif. The results of the Community Services show that there are several obstacles experienced by PD Nesif related to time and commitment in managing the E-commerce Accounts that they already have.

Keywords: E-Commerce, MSME, PD Nesif

\section{PENDAHULUAN}

UMKM mempunyai peranan penting dan strategis dalam pembangunan ekonomi nasional. UMKM juga terbukti tidak terpengaruh terhadap kirisis. Data dari Badan Pusat Statistik menunjukkan bahwa setelah masa krisis ekonomi jumlah UMKM tidak mengalami penurunan dan terus meningkat serta mampu menyerap 85 juta hingga 107 juta tenaga kerja sampai tahun 2012. Pada tahun itu jumlah pegusaha di Indonesia sebanyak 56.539.560 unit. Dari jumlah tersebut, sebanyak 56.534.592 unit adalah UMKM atau 99,99\%. Sisanya sekitar $0,01 \%$ merupakan usaha termasuk kategori besar. Hal itu membuktikan bahwa UMKM terus tumbuh dan mampu beridiri sebagai pelaku ekonomi yang tangguh, unggul serta tahan krisis. 
Dalam hal pemasaran, UMKM seyogyanya dapat memanfaatkan peluang pengembangan jangkauan wilayah pemasaran melalui kemajuan teknologi. Bauran pemasaran terdiri dari segala sesuatu yang dapat dilakukan perusahaan untuk mempengaruhi permintaan produknya [1]. Bauran pemasaran merupakan satu dari sekian konsep yang paling universal yang telah dikembangkan dalam pemasaran dan sebagian besar memusatkan pada empat komponen kunci, yaitu Product (Produk), Promotion (Promosi), Price (Harga Jual), dan Place (Tempat).

Perkembangan teknologi harus dapat dimanfaatkan secara optimal oleh UMKM agar mampu bertahan ditengah gencarnya pemasaran produk-produk impor di berbagai marketplace online. Penggunaan $e$ commerce lebih efisien, kemudahan bertransaksi, pengurangan biaya dan mempercepat proses transaksi [2].

PD Nesif merupakan salah satu UMKM Produsen Makanan Ringan yang berada di Desa Dayehmanggung Kecamatan Cilawu Garut. Skema penjualan PD NESIF sangat tradisional [3]. Skema penjualan adalah dengan penitipan produk makanan ringan pada beberapa Toko yang diperkirakan dapat menjangkau konsumen. Skema tersebut memiliki kekurangan pada PD Nesif, yakni terdapat ketidakpastian dalam keuntungan dan terdapat resiko barang dikembalikan karena kadaluarsa. Resiko barang dikembalikan tentu saja menjadi resiko paling merugikan bagi PD Nesif. Tujuan dilakukan Kegiatan Pengabdian pada
Masyarakat (PkM) Prodi Teknik Industri pada PD Nesif adalah untuk merubah paradigma berpikir dari pihak UMKM (PD Nesif) dalam memandang teknologi sebagai jalan untuk pengembangan dan keberlangsungan keberadaan UMKM di masa yang akan datang serta memberikan perancangan Pemasaran Online. Diharapkan dengan pemasaran Online tersebut, dapat meningkatkan keuntungan PD Nesif.

\section{METODE}

Metode Pengabdian Pada Masyarakat yang dilakukan pada PD NESIF adalah dengan memberikan perancangan dan Pelatihan pada penggunaan teknologi, dalam hal ini adalah ECommerce. Penggunaan Ecommerce saat ini sangat digemari oleh masyarakat. Data yang digunakan adalah Data Primer yakni Terkait Produk-produk PD Nesif beserta jalur pemasaran yang dilakukan. Teknik Pengumpulan Data dilakukan dengan Observasi, Wawancara, dan Dokumentasi.

Permasalahan yang dihadapi oleh PD Nesif adalah terkait resiko dikembalikannya produk PD Nesif, dimana hal ini merupakan kerugian yang harus ditanggung dalam bisnis. Prodi Teknik Industri menyarakan PD Nesif menggunakan Teknologi yang diharapkan meningkatkan keuntungan dan menurunkan Resiko tersebut. Penggunaan Teknologi yang dimaksudkan adalah dengan implementasi Ecommerce. Ada beberapa kelebihan yang dimiliki E-Commerce dan tidak dimiliki oleh transaksi bisnis yang dilakukan secara offline, yakni Banyaknya jenis produk yang 
ditampilkan, Tempat menjual produk yang memiliki domain dan hosting, Cara menerima pesanan melalui E-mail, telpon, sms dan akun media sosial, Cara pembayaran berupa cashless dan Tunai, Metode pengiriman yang bekerjsaam dengan perusahaan pengiriman, tersedianya Customer service: E-mail, Contact us, Telepon, Chat dan lainnya (Hidayat, 2008 dalam [2].

Perangkat keras yang digunakan adalah Handphone berbasis Android. Perangkat lunak yang digunakan adalah Instagram dan Shopee yang diunggah melalui Playstore. Tahapan implementasi E-commerce adalah Ekspolarasi, Instalasi, Implementasi awal, Implementasi Penuh, Ekspansi dan Pelatihan Pegawai [2].

\section{HASIL DAN PEMBAHASAN}

Bauran pemasaran menjadi kunci penting dalam penjualan di E-commerce karena perusahaan bisa langsung menerima feedback berupa masukan atau saran langsung dari konsumen setelah barang diterima. Promosi adalah salah satu kegiatan dalam Bauran Pemasaran, termasuk penggunaan unsur teknologi yakni Pemasaran Online.

Tahap pertama perancangan pemasaran online adalah dengan memberikan penjelasan tentang penggunaan teknologi. Pada proses penjelasan teknologi, PD Nesif cukup antusias dengan diskusi tersebut. Pada diskusi ini juga jelaskan media sosial dan akun bisnis Toko online yang dapat dipilih. Langkah kedua adalah dengan membuatkan akun PD Nesif dengan data primer yang sudah diberikan. Jenis E-commerce yang dilakukan atau dpilih oleh PD.NESIF adalah Consumer to Consumer (C2C). Consumer to Consumer merupakan E-commerce yang meliputi semua transaksi elektronik barang dan jasa antar konsumen. Umumnya transaksi ini dilakukan melalui pihak ketiga yang menyediakan platform online untuk melakukan transaksi tersebut.

Perancangan Pemasaran online yang dilakukan adalah dengan membuat terlebih dahulu akun yang dibuat Instagram dan Shopee. Instagram dipilih karena beberapa pertimbangan yakni, pertama, adanya penelitian yang mendukung keputusan tersebut yakni Penggunaan Instagram cukup efektif bagi kalangan pengusaha rumahan terutama Wanita [4]. Kedua, Instagram adalah media sosial terbesar ketiga di Indonesia dengan Total 91,77 orang pengguna [5].

Adapun pemilihan Shopee sebagai akun baru adalah karena, pertama, Shopee memiliki jumlah pengguna yang aktif di Indonesia sebesar 274 Juta Pengguna Aktif pada tahun 2021 [6], kedua hasil survey dari KIC yang menyatakan bahwa 85\% UMKM merasakan manfaat dalam memasarkan produk lewat Shopee [7], dan terakhir, penelitian yang berkaitan dengan customer Satisfaction Index Shopee yakni Kinerja dari Penerapan E Service Quality pada Aplikasi Shopee adalah baik dan Customer Satisfaction index berada pada level puas [8]. 


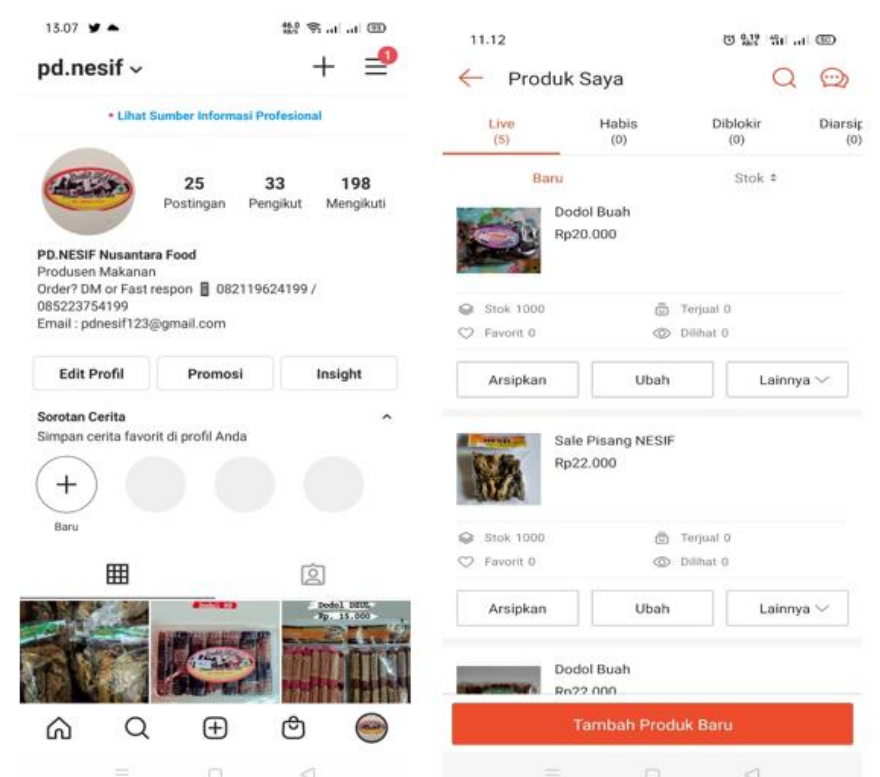

Gambar 1 : Akun PD Nesif, Instagram (Kiri), Shopee (Kanan)

Setelah menyediakan akun, kemudian diberikan pelatihan dan pendampingan dalam pemasaran online kepada PD Nesif. Dalam proses pendampingan, sempat terjadi beberapa transaksi dan berhasil dilakukan. Dalam beberapa waktu, PD Nesif diarahkan untuk melakukannya secara mandiri. Hasil Evaluasi menunjukkan bahwa Penggunaan Pemasaran Online pada PD Nesif, belum dapat dirasakan manfaatnya secara langsung. Hal ini terkait dengan kendala yang dialami oleh PD Nesif. Kendala yang terjadi adalah kebutuhan waktu bagi PD.NESIF dalam beradaptasi dengan pemasaran online sehingga masih banyak kekurangan yang harus diperbaiki dalam pemasaran online dan komitmen PD Nesif dalam menjangkau konsumen yang lebih besar. Hal ini dapat disolusikan dengan memberikan operator yang dapat menangani dan mengelola kompleksitas dari pemasaran online. Jika iklan online dikelola oleh orang menguasai internet dan desainnya, maka menjadi efektif dan dapat menarik banyak perhatian konsumen [9].

\section{PENUTUP}

Pemasaran online menjadi sebuah terobosan baru bagi PD.NESIF dalam melaksanakan penjualan. Kegiatan yang dilakukan pada PkM yakni Perancangan dan pelatihan pengelolaan sistem pemasaran online PD.NESIF. E-commerce yang menjadi pasar PD.NESIF adalah Shopee dan Instagram. Terdapat beberapa kendala yang dialami oleh PD Nesif yang berkaitan dengan waktu dan komitmen dalam pengelolaan Akun Ecommerce tersebut.

Hasil evaluasi pengabdian pada masyakarat yakni pada UMKM PD Nesif memberikan harapan baru bagi PD Nesif untuk lebih mengenal dan mempertimbangnkan teknologi dalam pemasaran yang dilakukan. 
Pengembangan pemasaran online diharapkan mampu meningkatkan keuntungan PD.NESIF dimasa kini dan mendatang.

\section{DAFTAR PUSTAKA}

[1] Hermawan, Haris, "Analisis Pengaruh Bauran Pemasaran Terhadap Keputusan, Kepuasan Dan Loyalitas Konsumen Dalam Pembelian Roti Ceria Di Jember," . 2015.[Online] Available: https://jurnal.unej.ac.id/index.php/BI SMA/article/view/5904

[2] Maulana, Shabur Miftah., Susilo, Heru., Riyadi. "Implementasi $E$ Commerce Sebagai Media Penjualan Online (Studi Kasus Pada Toko Pastbrik Kota Malang)," Jurnal Administrasi Bisnis (JAB), Vol 29 No 1 , 2015 [Online] Available: https://media.neliti.com/media/publicat ions/86512-ID-none.pdf.

[3] Nurwathi, Ade Geovania Azwar, Novi Mardiana, Ahmad Munandar, Djoko Pitoyo, Inayati Nasrudin, Sofiani Nalwin Lina Nurhayati. Pendampingan Proses Produksi Makanan Ringan Di PD. Nesif Desa Dayeuh Manggung Kabupaten Garut. Jurnal Abdimas Sang Buana, Volume 02 No 01. 2021. [Online] Available: http://jurnal.usbypkp.ac.id/index.php/ Abdimas_Sang_Buana/article/view/63 3 . Diakses: 27 Agustus 2021

[4] Wally, Eman and Koshy, Swapna, "The use of Instagram as a marketing tool by Emirati female entrepreneurs: an exploratory study" 2014, Hal 1-19. [Online] Available https://ro.uow.edu.au/dubaipapers/6 21

[5] Databoks.katadata.co.id, 2021, [Online] Available: https://databoks.katadata.co.id/data publish/2021/08/03/inilah-negarapengguna-instagram-terbanyakindonesia-urutanberapa\#: :text=Di\%20Indonesia\%2 C\%20jumlah\%20pengguna\%20Inst agram,sebesar\%2091\%2C77\%20jut a\%20pengguna. Diakses tanggal 29 Agustus 2021, 21.00 WIB

[6] Ginee.com, 2021, [Online] Available:

https://ginee.com/id/insights/jumlah -pengguna-marketplace-android/

Diakses tanggal 29 Agustus 2021, 21.10 WIB

[7] Katadata.co.id, 2021, [Online] Available:

https://katadata.co.id/yuliawati/digit al/608fc9fd30bac/survei-kicmayoritas-umkm-berdagangonline-di-shopee-dan-tokopedia Diakses tanggal 29 Agustus 2021, 21.20 WIB

[8] Sastika,Widya, "Analisis Kualitas Layanan Dengan Menggunakan EService Quality Untuk Mengetahui Kepuasan Pelanggan Belanja Online Shoppe (Studi Kasus : Pelanggan Shopee Di Kota Bandung 2017)," Ikraith-Humaniora, Vol 2, No 2, 2018. [Online] Available:http://journals.upiyai.ac.id/index.php/ikraithumaniora/article/download/127/56

[9] Santoso, Erica Delia, Novia Larasati, "Benarkah Iklan Online Efektif Untuk Digunakan Dalam Promosi Perusahaan, Jurnal Ilmiah Bisnis dan Ekonomi Asia, Volume 13, No 1, Hal 28-36, 2019. [Online] Available:

https://jurnal.stie.asia.ac.id/index.php/j ibeka/article/download/99/89 